\title{
Cidades Globais 2012: 0 Cenário Asiático
}

\section{Leonardo Mercher ${ }^{1}$}

\section{RESUMO}

A atualização do índice geral de cidades globais, em 2012, pela A.T. Kearney and The Chicago Council, indica que a Ásia perdeu espaço no cenário internacional, como reflexo das novas posições de suas cidades.

Palavras-chave: Ásia. Cidade Global.

A publicação feita pela revista norte-americana Foreign Policy, em 2008, trouxe um índice das sessenta cidades globais mais importantes no cenário internacional de acordo com as pesquisas da A.T. Kearney e The Chicago Council baseadas na participação de diversos especialistas como a Saskia Sassen. 0 diferencial desse índice de cidades globais foi subdividi-lo em cinco outros índices temáticos, condizendo com a atuação dessas cidades, sendo: atividades econômicas; troca de informações; engajamento político; capital humano e experiência cultural. 0 objetivo dessa pesquisa, representada nos índices de 2008 e 2012, seria o de identificar os polos humanos onde as principais dinâmicas internacionais ocorreriam e, seguindo as ideias de hierarquia urbana internacional (GEDDES, 1915), atualizar a compreensão desses novos atores internacionais.

As grandes cidades de importância internacional, que passam a ser compreendidas como globais, foram classificadas em sessenta posições no índice de 2008, que, ao se comparar com o novo índice de 2012, com sessenta e seis posições, é possível identificarem-se algumas alterações no número de reconhecimento das cidades globais, contabilizando 66, bem como a mobilidade dentro do próprio índice. Tanto em 2008 como 2012, vinte e cinco cidades asiáticas fazem parte das maiores cidades

\footnotetext{
${ }^{1}$ Leonardo Mercher é Mestrando em Ciência Política pela Universidade Federal do Paraná. 
globais. Entretanto, dessas 25 cidades listadas nos índices, 20 caíram de posição, três se mantiveram no mesmo lugar (Tóquio, Hong Kong e Bangalore) e apenas duas (Seul e Mumbai) subiram de posição.

O mais importante a ressaltar é que as cidades com maior queda de posições foram justamente as asiáticas, que cederam espaço para quatro cidades norteamericanas e europeias (Barcelona, Montreal, Genebra e Houston), uma australiana (Melbourne) e uma africana (Nairóbi). Ao todo, seis cidades foram reconhecidas como importantes, a serem incluídas nas atualizações do índice de 2008, forçando diversas cidades a caírem em suas posições gerais. Singapura caiu quatro posições, Pequim duas, Shangai uma, Dubai duas, Istambul nove, Taipei seis, Bangkok 21 posições, Tel Aviv quatro, Osaka duas, Nova Deli sete, Kuala Lumpur nove, Manila cinco, Jacarta seis, Guangzhou oito, Ho Chi Minh seis, Karachi cinco, Dhaka sete, Calcutá quatro, Shenzhen onze e Chongqing sete.

Entretanto, essa queda não pode ser explicada apenas pela inclusão de mais seis cidades no índice, visto que quedas como de Bangok, Shenzhen ou Istambul ultrapassaram muito mais do que as novas posições. Uma possível explicação seria a perda comparativa dentro dos cinco critérios, visto que, se antes boa parte dessas cidades asiáticas ocupavam posições mais elevadas, isso se dava pelo fato de terem o índice de atividades comerciais muito elevado, em comparação com suas atuações nas outras áreas temáticas, como experiência cultural ou engajamento político. Singapura, Shangai, Kuala Lumpur, Ho Chi Minh e Calcutá foram alavancadas à lista de 2008 justamente por apresentarem um melhor índice nas atividades comerciais do que em todas as demais áreas investigadas na seleção. Ao serem incluídas cidades com grande desenvolvimento em outras áreas temáticas, essas tiveram uma queda significativa de posições gerais.

No geral, soma-se, ainda, a essa queda um maior desenvolvimento das demais cidades como Buenos Aires e Sidney, que subiram onze e quatro posições, respectivamente. Se dentre as seis primeiras cidades no índice geral de 2012 houve uma manutenção das posições de 2008, da sétima posição em diante a dinâmica de alteração (queda e ascensão) se fez presente, mas com poucas alterações significativas às cidades não-asiáticas. Pode-se dizer que dentre os Estados asiáticos com maior inclusão de suas 
cidades no índice tem-se: China (Hong Kong², Pequim, Xangai, Guangzhou, Shenzhen e Chongqing) e Índia (Mumbai, Nova Deli, Bangalore e Calcutá). Mas dentre as posições gerais de suas cidades a China teria um melhor reconhecimento de seus entes subnacionais.

Ainda que o Japão possua duas cidades, sendo Tóquio a mais bem posicionada no índice geral (a segunda cidade japonesa é Osaka), há um predomínio em números de cidades chinesas e indianas, fortalecendo a ideia de maior inserção internacional de Estados emergentes: "Cities in the BRIC countries of Brazil, Russia, India and China have been steadily working their way to the top of the GCI over the past four years when assessed against the business dimension only"3 (KHALLASH, 2012). Já as demais áreas asiáticas, como o Oriente Médio, possuem cidades listadas, entretanto cabem ao Extremo Oriente e à Índia maior participação nessa nova atualização do índice de cidades globais 2012.

O cenário subnacional asiático atual, ao nível das cidades globais, mostrou-se decrescente em relação às posições ocupadas em 2008, sugerindo que as cidades europeias e norte-americanas ainda possuem maior peso dentro das dinâmicas da paradiplomacia global. Ainda que cidades chinesas e indianas ampliem o número desses atores no índice global, cidades europeias e norte-americanas continuam com as posições mais altas e isso se deve pelo desenvolvimento das demais áreas temáticas, como política e cultura. Tóquio, Hong Kong e Seoul são as cidades mais bem posicionadas, entretanto, não representam a realidade da maioria asiática. 0 cenário internacional asiático, ao nível paradiplomático, ainda está preso ao desenvolvimento comercial e econômico, diminuindo em muito o potencial de influência nas dinâmicas paradiplomáticas globais.

\footnotetext{
${ }^{2}$ Hong Kong é uma região administrativa especial chinesa tratada como uma Cidade-Estado (RAE).

3"As cidades dos países pertencentes ao BRIC (Brasil, Rússia, Índia e China) vem continuamente trabalhando seus caminhos para o topo do índice (Global Cities Index) pelos últimos quatro anos, se avaliadas em relação à dimensão atividades comerciais". Tradução livre.
} 


\section{Referências Bibliográficas}

A.T. Kearney Global Management Consultants and The Chicago Council of Global Affairs. The 2008 Global Cities Index. Washington: Foreign Policy Magazine, pp.68-76, nov./dez. 2008.

GEDDES, Patrick. Cities in evolution. Londres: Williams \& Norgate, 1915.

KHALLASH, Sally. 2012 Global Cities Index. Global Talents Strategy: http://globaltalentstrategy.com/en/article/2012-global-cities-index-169. Publicado em 04 de jun. de 2012. Acessado em 22 de nov. de 2012. 